Jurnal Pembangunan Pendidikan: Fondasi dan Aplikasi

Volume 5, No 2, December 2017 (187-198)

Online: http://journal.uny.ac.id/index.php/jppfa

\title{
PENDIDIKAN KARAKTER DALAM SERAT TRIPAMA KARYA MANGKUNEGARA IV
}

\author{
Novia Wahyu Wardhani, Noeng Muhadjir \\ Universitas Negeri Semarang \\ noviawahyu@mail.unnes.ac.id
}

\begin{abstract}
Abstrak
Tujuan penelitian ini adalah untuk menggali kembali nilai-nilai kearifan lokal masa lalu seperti dalam Serat Tripama Karya Mangkunegara IV sehingga dapat dibedakan mana yang harus diteladani dan mana yang tidak tetapi dapat dijadikan materi analisis nilai dalam pembelajaran. Metode yang digunakan adalah metode kualitatif dengan pendekatan interpretasi, hermeneutik, dan verstehen. Teknik analisis yang digunakan adalah analisis data model interaktif yang terdiri dari pengumpulan data, reduksi data, penyajian data, dan verifikasi. Hasil penelitian ini adalah tidak seтиa nilai dapat dijadikan sumber keteladanan bagi pembentukan karakter peserta didik. Nilai yang dapat diteladani adalah nilai niat yang baik, pengabdian yang tulus disertai dengan usaha, dan kerelaan berkorban pada kebenaran.
\end{abstract}

Kata kunci: pendidikan karakter, serat tripama, Mangkunegara IV

\section{CHARACTER EDUCATION IN SERAT TRIPAMA BY MANGKUNEGARA IV}

Novia Wahyu Wardhani, Noeng Muhadjir

Universitas Negeri Semarang

noviawahyu@mail.unnes.ac.id

\begin{abstract}
The purpose of this research is to dig again values local knowledge the past as work in the Serat Tripama Mangkunegara iv so as to be distinguishable which one to role models all and which ones have not but can be used as matter analysis value in learning. Methods used was a qualitative methodology with the approach interpretation, hermeneutic, and verstehen. Technique the analysis used is interactive data analysis model consisting of data collection, reduction data, presentation of data, and verification. The result of this research is not all value can be used as a source of exemplary for the establishment of character school tuition. Value that can be role models all is the value of good reasons, devotion sincere accompanied by business, and mutual consent sacrifice to the truth.
\end{abstract}

Keywords: character education, serat tripama, Mangkunegara IV 


\section{PENDAHULUAN}

Kajian-kajian budaya masa lalu merupakan upaya yang sangat penting untuk dilakukan dalam menggali khasanah kearifan yang berguna bagi generasi muda. Hal itu dapat menjadi alternatif dalam menemukan nilainilai pegangan, pedoman, atau setidaknya sebagai perbandingan bagi generasi sekarang dalam menghadapi perubahan dunia yang semakin pesat (Abdullah, 2006, p. 1). Dieter (2006, p. 156) mengatakan bahwa (a) seni tradisi tidak ketinggalan zaman, melainkan bentuk peninggalan yang menceritakan tentang dasar-dasar setiap budaya (asal terjadinya proses pembelajaran tersebut); (b) seni tradisi mesti dianalisis secara teliti untuk menemukan berbagai unsur dasar yang kemudian dapat menjadi elemen praktik sederhana tetapi spesifik bagi anak; (c) seni tradisi juga memiliki unsur-unsur nilai-nilai abadi. Dengan menggali kembali khasanah budaya yang kaya akan nilai-nilai kearifan lokal maka akan didapatkan suatu konsep pedidikan sebagai proses pewarisan budaya. Sistem budaya lokal merupakan modal sosial (social capital) yang besar, telah tumbuhberkembang secara turuntemurun yang hingga kini kuat berurat-berakar di masyarakat (Hikmat, 2010, p. 169).

Jawa memiliki banyak nilai-nilai luhur yang dapat digali dari karya-karya sastra pujangga dan raja pada zaman dahulu. Salah satunya adalah karya sastra Kanjeng Gusti Pangeran Adipati Arya (KGPAA) Mangkunegara IV. Kemampuannya dalam bersasatra menghasilkan banyak karya, salah satunya adalah Serat Tripama.

Serat Tripama merupakan karya sastra berbentuk tembang macapat, pupuh dhandanggula yang berjumlah tujuh bait. Tripama diterbitkan pertama kali dalam kumpulan karya KGPAA Mangkunegara IV, jilid III tahun 1927. Serat tripama berisi ajaran keprajuritan, tiga tokoh pawayangaan yang ditampilkan sebagai teladan pada masanya. Tiga tokoh pewayangan tersebut yaitu Patih Suwanda, Kumbakarna, dan Adipati Karna. Patih Suwanda diceritakan pada masa Pra-Ramayana yang memiliki keinginan mengabdi yang besar kepada raja dengan mendayagunakan seluruh kemampuan yang dia miliki. Kedua, Kumbakarna yang ada pada masa Ramayana. Kumbakarna merupakan raksasa yang memiliki keteladanan berani mati untuk kemerdekaan tanah airnya yang pada waktu itu diserang oleh tentara kera Sri Rama. Ketiga, Busukarna atau Adipati Karna yang dikisahkan pada masa Mahabarata yang setia kepada Duryudhana yang telah mengangkat derajatnya dari rakyat jelata menjadi seorang raja.

Serat ini ditulis oleh KGPAA Mangkunegara IV dengan tujuan agar dijadikan sebagai panutan dan sumber inspirasi untuk diambil suri tauladanya. Sebagaimana yang telah diungkapkan oleh Saputro (2001, p. 21) bahwa Serat tripama merupakan serat piwulang yaitu suatu jenis karya sastra yang kandungan isinya merupakan petuah, pesan, ajaran, pedoman, tuntunan ataupun bimbingan. Serat ini tidak hanya ditujukan bagi prajurit tetapi juga para pemimpin dan masyarakat agar mampu melaksanakan tugas sesuai peran dan fungsinya masing-masing.

Nilai-nilai dalam Serat Tripama Karya KGPAA Mangkunegara IV tersebut dirasa perlu untuk dimunculkan kembali dan dilestarikan sebagai teladan untuk memperbaiki moral bangsa. Hal ini perlu segera dilakukan karena melihat fenomena yang terjadi dewasa ini. Seiring dengan datangnya arus globalisasi, tanda-tanda kurangnya rasa nasionalisme rakyat terhadap negara Indonesia mulai bermunculan. Fenomena yang dapat kita lihat adalah gaya hidup kebarat-baratan yang lebih disukai masyarakat. Selain itu, masyarakat juga lebih bangga memakai produk luar negeri dan bahkan lebih bangga tinggal dan bekerja di luar negeri.

Serat Tripama sebagai sebuah karya sastra telah mampu menghadirkan banyak kisah keteladanan yang kemudian dapat dikembangkan sebagai salah satu sumber pengembangan pendidikan karakter bagi generasi muda (Supriyono \& Sutono, 2014, pp. 42-52). Selain itu Ketiga tokoh Tripama apabila dikorelasikan dengan pendidikan karakter bagi generasi muda memiliki relevansi yang cukup bermanfaat. Nilai-nilai yang terkandung dalam karakter tokoh Tripama tersebut apat diaplikasikan pada bidang maupun kompetensi apapun. Secara konsep nilai yang mulia dalam Tripama masih sangat relevan untuk diterapkan di zaman sekarang (Cahyono, 2015). Nilai-nilai nasionalisme yang akan dicoba untuk dikembangkan melalui teladan dari Serat Tripama akan mendukung pengembangan nilai dalam tujuan pendidikan nasional yaitu 
membangun semangat kebangsaan dan cinta tanah air.

Dari latar belakang masalah tersebut, penulis berkeinginan untuk menggali kembali nilai-nilai kearifan lokal yang ada dalam Serat Tripama karya Mangkunegara IV dan implikasinya dalam dunia pendidikan di Indonesia khususnya dalam memperkuat karakter bangsa.

\section{METODE PENELITIAN}

Penelitian ini adalah jenis penelitian kualitatif. Penelitian kualitatif merupakan metode yang paling baik digunakan untuk mengungkap suatu budaya, sehingga dapat menggali data-data yang mendalam dan bermakna

Penelitian ini dilakukan selama 2 tahun mulai dari 2016-2017 di Keraton Mangkunegaran Surakarta. Target/subjek penelitian terdiri dari 3 bidang yaitu: kerabat keraton, akademisi, dan budayawan. Subjek penelitian berasal dari Jawa Tengah. Kerabat Keraton terdiri dari abdi keraton dan lulusan sekolah pedalangan Mangkunegaran. Akademisi merupakan dosen bahasa dan sastra dari UNNES dan budayawan dari Surakarta.

Di dalam penelitian ini, penulis melakukan analisis dokumen atau data verbal yang dikembangkan dan ditegaskan melalui proses wawancara, observasi, dan dokumentasi. Pendekatan yang dipakai adalah interpretasi, hermeneutik dan verstehen. Tahap-tahap dalam penelitian ini adalah (1) menangkap objek material, mengiventarisasi data empiris "simple ideas" berupa teks, memahami simbol-simbol (tahap simbolik) yang sudah dilakukan proses analisis isi dan struktural; (2) memberi dan menggali secara cermat tentang makna (sistem nilai, kebudayaan manusia, gejala-gejala) yang terkandung dalam objek; (3) melakukan pemahaman melalui insight, einfuehlung, serta akal budi untuk menemukan makna simbol secara esensial filosofis; (4) melakukan interpretasi.

Teknik analisis data adalah cara yang digunakan untuk menganalisis data yang sudah diperoleh pada awal, proses, dan akhir penelitian. Data kemudian disajikan menggunakan model analisis interaktif yang terdiri dari tiga alur kegiatan. Tiga alur tersebut terjadi secara bersamaan yaitu melalui pengumpulan data, reduksi data, penyajian data, dan penarik- an kesimpulan/verifikasi (Miles \& Huberman, 1992, p. 16).

Aktivitas yang dilakukan untuk memperoleh dan menganalisis data dimulai dari langkah-langkah sebagai berikut: (1) mencari dan mengumpulkan naskah yang ada mengenai Serat Tripama karya Mangkunegara IV terbitan Java Institut; (2) menerjemahkan naskah asli Serat Tripama yang bertuliskan Jawa kuno ke dalam bahasa Indonesia; (3) mencatat semua data mengenai Mangkunegara IV yang diperoleh darihasil observasi dan wawancara; (4) memilih hasil data yang pokok dan penting sesuai dengan kebutuhan data yang diperlukan; (5) menginterpretasikan dan menafsirkan data yang sudah melalui proses pengelompokan data; (6) menyajikan data secara diskriptif dari hasil reduksi data dalam bentuk teks; yang dilengkapi dengan menambahkan tabel dan gambar-gambar untuk melengkapi dan memperjelas hasil sajian data; (7) melakukan verifikasi.

\section{HASIL PENELITIAN DAN PEMBAHASAN}

Serat Tripama adalah salah satu karya Mangkunegara IV yang ditulis pada tahun 1860 -an di Surakarta. Serat Tripama merupakan karya sastra berbentuk tembang macapat pupuh dhandanggula yang berjumlah tujuh bait. Serat Tripama diterbitkan pertama kali dalam kumpulan karya Mangkunegara IV jilid III (1927) yang diterbitkan oleh Java Institut dan yayasan Mangadeg.

Serat Tripama artinya serat yaitu tulisan atau naskah, sedangkan Tripama terdiri dari dua kata yaitu Tri yang berarti tiga dan Pama yang berarti perumpamaan.Tripama secara umum berisi nasehat mengenai keteladanan tiga tokoh wayang yaitu Patih Suwanda atau Bambang Sumantri dalam cerita praRamayana, Kumbakarna dalam cerita Ramayana, dan Adipati Karna dalam cerita Mahabarata. Dibawah ini merupakan esensi yang tersirat dan tersurat dalam Serat Tripama.

Dengan demikian, penelitian ini mencoba mengungkapkan makna berdasarkan pemaknaan bahasa Jawa sesuai dengan apa yang ada pada teks yang akan diuraikan dalam beberapa subbab yaitu: a. Patih Suwanda; b. Kumbakarna; c. Adipati Karna; dan d. Pendidikan Karakter dalam Serat Tripama Karya Mangkunegara IV. 


\section{Patih Suwanda}

Patih Suwanda memiliki nama sewaktu kecil Bambang Sumantri. Sumantri dalam bahasa Sansekerta terdiri kata $S u$ yang berarti lebih dam Mantri yang berarti kebijaksanaan. Patih Suwanda adalah tokoh dalam cerita Pra-Ramayana. Dia merupakan anak begawan (pertapa) Suwandagni dari pertapan Arga Sekar (Ardi Sekar). Begawan Suwandagni adalah keturunan dari Batara Surya. Dia adalah pertapa yang tinggal di daerah pegunungan.

Bambang Sumantri adalah anak pertama dari dua bersaudara. Dia memiliki adik yang bernama Bambang Sukrasana (Sukasarana). Sukrasana tidak memiliki kesamaan wujud secara lahiriah dengan Sumantri. Dia lahir dengan wujud raksasa kecil yang biasa disebut buta bajang, sedangkan Sumantri berbadan tinggi gagah. Selain itu Sukrasana memiliki banyak luka di badannya sehingga parasnya buruk sedangkan Sumantri berparas tampan.

Sumantri sejak kecil sudah mendapatkan berbagai ilmu wigati yaitu ilmu pengetahuan, ilmu pemerintahan, dan juga secara fisik sudah dipersiapkan menjadi seorang prajurit yang dapat diandalkan. Pendidikan dan pelatihan tersebut, diperoleh dari ayahnya Begawan Suwandagni. Sumantri memiliki motivasi kuat untuk selalu unggul. Dia juga memiliki senjata mematikan berupa Cakra Baskara atau Cakra Biswara atau Cakra Sudarsana pemberian dari Batara Wisnu.

Dalam dunia pewayangan senjata cakra digambarkan berbentuk roda dengan gigi-gigi yang menyerupai mata tombak. Namun, dalam Wayang Purwa senjata cakra digambarkan seperti mata panah. Senjata cakra yang dimiliki oleh Sumantri merupakan senjata Batara Wisnu. Dia mendapatkan senjata tersebut karena Sumantri merupakan orang yang dikasihi oleh Batara Wisnu. Senjata ini juga dimiliki oleh para titisan Batara Wisnu seperti Krisna dalam cerita Mahabarata.

Menuju kedewasaannya, Sumantri memiliki tekad yang kuat untuk mengabdi kepada Raja Maespati yang bernama Prabu Arjuna Sasrabahu yang merupakan titisan dewa Wisnu. Tekad kuat Sumantri direstui oleh ayahnya. Akan tetapi, dia tidak mau membawa adiknya ikut serta bersamanya, karena adiknya adalah raksasa yang buruk wajahnya. Ketidakmauannya disebabkan takut perjalanannya terhambat karena sosok adiknya yang menakutkan, meskipun adiknya memiliki kemampuan yang sama hebatnya.

Sukrasana adalah orang yang dikasihi oleh Batara Dharma karena selama hidupnya dia memiliki budi yang luhur. Dia tidak pernah menyakiti binatang. Dari budinya tersebut Sukrasana diberikan kemampuan oleh Batara Dharma yaitu dapat menjinakkan binatang buas. Tidak hanya itu, Sukrasana juga memiliki cinta kasih yang tinggi kepada kakaknya sehingga ketika Sumantri tidak mengizinkannya untukikut, timbul kekecewaan di hatinya.

Sesampainya Sumantri di Mahespati, ia mengutarakan maksud serta tujuannya. Prabu Arjuna Sasrabahu dengan senang hati menerima keinginan Sumantri untuk mengabdikan diri padanya dan Negerinya Mahespati. Selama pengabdiannya, Bambang Sumantri berganti nama dan dikenal dengan sebutan Patih Suwanda.

Proses pengabdian Patih Suwanda kepada Arjuna Sasrabahu sampai pada akhir kehidupannya, merupakan karakter yang patut untuk dijadikan suri tauladan. Oleh sebab itu, Mangkunegara IV menuliskan keteladanannya ke dalam Serat Tripama pupuh dandanggula pada bait (pada) pertama dan kedua, sebagai berikut.
Yogyanira kang para prajurit,
Lamun bisa samya anulada,
Kadya nguni caritane,
Andelira sang Prabu,
Sasrabau ing Maespati,
AranPatih Suwanda,
Lalabuhanipun,
Kang ginelung tri prakara,
Guna kaya purunne kang denantepi,
Nuhoni trah utama,

Artinya :

Seyogianya para prajurit,

Bila dapat semuanya mencontoh,

Seperti masadahulu,

Andalan sang Prabu,

Sasrabau di Maespati,

Bernama Patih Suwanda,

Jasa-jasanya,

Yang dipadukan dalam tiga hal,

Pandai, mampu, dan berani yang

ditekuninya,

Menepati sifat keturunan utama. 
Selanjutnya dijelaskan dalam bait kedua yaitu:

Lire lalabuhan tri prakawis, Guna bisa saniskareng karya, Binudi dadi unggule,

Kaya sayektinipun,

Duk bantu prang Manggada nagri,

Amboyong putri dhomas,

Katur ratunipun,

Purunne sampun tetela,

Aprang tandhing lan ditya Ngalengka aji, Suwanda mati ngrana.

Artinya: :

Arti jasa bakti yang tiga macam itu, Pandai mampu di dalam segala pekerjaan,

Diusahakan memenangkannya,

Seperti kenyataannya,

Waktu membantu perang negeri

Manggada,

Memboyong delapan ratus orang puteri,

Dipersembahkan kepada rajanya,

Keberaniannya sudahlah jelas,

Perang tanding melawan raja raksasa

Ngalengka,

Suwanda meninggal dalam perang.

Tembang diatas secara garis besar berisi tentang karakter dan tekad yang dimiliki Patih Suwanda ketika akan dan pada saat mengabdi kepada Prabu Arjuna Sasrabahu. Tiga hal yang terlukiskan dalam tembang tersebut adalah karakter Patih Suwanda yang oleh Mangkunegara IV dianggap unggul yaitu guna, kaya dan purun. Guna (pandai), kaya (mampu), purun (berani) adalah tiga hal yang menjadi kelebihan Patih Suwanda.

Guna memiliki arti bahwa Patih Suwanda memiliki kecerdasan dan ketrampilan. Dia mampu menyelesaikan masalah dalam segala hal karena pengetahuan dan pengalamannya itu. Dia memiliki kepandaian untuk memberikan solusi bagi permasalahan yang dihadapi. Salah satu contohnya dalam cerita $\mathrm{Su}$ mantri Ngenger yang dibawakan oleh Ki Sugino Siswacarito. Dalam cerita tersebut, Patih Suwanda dapat melaksanakan tugas yang diberikan oleh Arjuna Sasrabahu untuk melamar Dewi Citrawati.

Cerita Sumantri Ngenger menceritakan tentang kisah Sumantri pada waktu telah menjadi Patih Suwanda. Pada cerita tersebut, Patih Suwanda diberi tugas oleh rajanya yaitu
Arjuna Sasrabahu untuk melamar dan membawa Dewi Citrawati, anak dari Raja Manggada yang sangat terkenal dengan kecantikannya. Saat sampai di sana, Patih Suwanda melihat Raja Manggada yang bernama Citrawijaya bingung. Setelah berkomunikasi ternyata kebingungan Citrawijaya disebabkan adanya 1000 raja yang ingin melamar Dewi Citrawati. Melihat kebingungan Citrawijaya tersebut, maka Patih Suwanda memberikan solusi agar diadakan sayembara. Akhirnya, sayembara diumumkan "siapa yang dapat mengalahkan Patih Suwanda maka lamarannya akan diterima”. Selama sayembara berlangsung, tidak satupun raja dari 1000 negara yang dapat mengalahkannya. Untuk menepati janjinya, akhirnya Citrawijaya menerima lamaran Prabu Arjuna Sasrabahu yang diwakilkan oleh Patih Suwanda.

Kaya atau dalam bahasa Indonesia berarti kemampuan, merupakan keunggulan kedua yang dimiliki oleh Patih Suwanda. Patih Suwanda dianggap memiliki kemampuan karena keberhasilannya melawan 1000 raja dan melamar Dewi Citrawati. Dalam lamaran tersebut, Patih Suwanda mampu memboyong harta benda dan putri raja. Namun demikian, kekayaan yang digambarkan dalam naskah Tripama ini memiliki makna bukan kekayaan dalam hal materi tetapi dalam hal nilai dan moral.

Secara materi, kekayaan yang dia peroleh sangat banyak berupa 800 orang puteri dari berbagai kerajaan dan harta benda lain. Adapun, kekayaan dalam hal moral adalah memiliki kesetiaan terhadap rajanya. Kesetiaan Patih Suwanda menjadikan keikhlasannya memberikan semua kekayaan yang dia peroleh dari keberhasilannya melaksanakan tugas kepada rajanya tanpa dia meminta sedikitpun sebagai imbalan.

Purun dalam bahasa Indonesia berarti mau atau bersedia. Purun dalam cerita ini menggambarkan kesanggupan dan keberaniannya dalam melaksanakan tugas-tugas dan membela negaranya. Keberanian Patih Suwanda dapat dilihat dalam cerita Suwanda Gugur.

Patih Suwanda gugur dalam perang melawan Raja Ngalengka yaitu Prabu Dasamuka. Perang ini berawal dari marahnya Prabu Dasamuka karena Ngalengka banjir oleh air yang dibendung oleh Prabu Arjuna Sasrabahu untuk mandi Dewi Citrawati dan 800 selirnya. Namun sesampainya di bendungan dan me- 
lihat Dewi Citrawati dan 800 selir mandi, keinginannya berubah menjadi ingin menguasai kerajaan dan semua yang ada di dalamnya termasuk Dewi Citrawati dan para selir Prabu Arjuna Sasrabahu.

Pada saat berperang melawan Prabu Dasamuka, Patih Suwanda sudah mengetahui bahwa dia akan gugur. Pengetahuannya diperoleh dari mimpinya bertemu dengan Sukrasana yang mengatakan ini akhir kehidupannya yang harus dia rasakan dan pada saatnya dia akan menjemputnya kenirwana. Mimpi tersebut tidak membuat Patih Suwanda mundur dari perang.

Pada saat perang berlangsung, tibatiba saja Sukrasana manjing (merasuki) gigi Prabu Dasamuka sehingga wajah Prabu Dasamuka seperti wajah adiknya, Bambang Sukasrana. Mengingatkan ia pada adiknya yang meninggal terkena senjata cakranya. Kejadian tersebut berawal pada saat pemindahan taman Sriwedari yang berhasil atas bantuan adiknya yaitu Sukrasana. Adiknya pun boleh ikut ke Mahespati tetapi tidak boleh menampakkan diri. Tanpa disengaja penampakan Sukrasana dilihat oleh para putri dan Dewi Citrawati sehingga menimbulkan kegaduhan. Patih Suwanda menghadapi kegaduhan yang disebabkan oleh adiknya, berpura-pura mengeluarkan cakra untuk membuat takut adiknya dan mengusirnya, namun tanpa sengaja cakra tersebut membunuh adiknya. Bayangan adiknya dan penyesalan atas kematian adiknya menjadikan dia lengah dan dengan mudah terbunuh oleh gigitan Prabu Dasamuka yang mengoyak tubuh Patih Suwanda. Kesanggupan Patih Suwanda inilah yang merupakan nilai ketiga yang pantas dijadikan teladan.

Ketiga hal tersebut menurut Mangkunegara IV, sudah semestinya dimiliki oleh orang-orang yang utama. Guna, kaya, purun merupakan keteladanan yang menurut Mangkunegara IV dapat kita jadikan contoh untuk mendidik generasi muda menjadi orang-orang yang unggul. Orang yang unggul adalah orang yang mau dan mampu melaksanakan tugasnya dengan baik untuk masyarakat, bangsa, dan negaranya tanpa mengharapkan imbalan apapun.

\section{Kumbakarna}

Kumbakarna masuk dalam salah satu tokoh Tripama, yang menurut Mangkunegara IV terdapat karakter baik dalam diri Kum- bakarna yang juga patut untuk dijadikan contoh. Kumbakarna adalah tokoh wayang yang terdapat dalam cerita Ramayana. Nama lengkap Kumbakarna adalah Raden Arya Kumbakarna. Ayah Kumbakarna adalah seorang resi bernama Begawan Wisrawa, sedang ibunya adalah Dewi Sukesi. Dia memiliki seorang kakak yaitu Dasamuka dan dua orang adik yaitu Sarpakenaka dan Gunawan Wibisana.

Begawan Wisrawa adalah seorang pertapa dari pertapaan Dederpenyu. Sebelum menjadi pertapa dia adalah raja dari lokapala dan Dewi Sukesi adalah anak dari Sumali, Raja Alengkadiraja. Kisah dalam lakon "Alap-Alap Sukesi" menceritakan seorang calon mertua yang jatuh cinta kepada calon menantunya, begitu juga sebaliknya. Begawan Wisrawa adalah ayah dari Raden Dhanapati yang menginginkan melamar Dewi Sukesi lewat ayahnya. Dewi Sukesi adalah putri yang cantik hingga kecantikannya diinginkan para raja termasuk pamannya yaitu Jambungmali.

Syarat untuk dapat mempersunting Dewi Sukesi adalah dapat mengalahkan Jambungmali dan menguasai pengetahuan tentang Sastra Jendra Hayuningrat Pangruwating Diyu. Begawan Wisrawa mampu mengalahkan Jambungmali dengan memenggal-menggal tubuhnya. Dia juga memiliki pengetahuan yang baik tentang Sastra Jendra Hayuningrat Pangruwating Diyu dan menyanggupi untuk mengajarkannya kepada Dewi Sukesi. Dengan demikian, lamarannyalah yang diterima.

Kalimat sastra jendra ada pada abad ke-19 (1820) dalam karya Kyai Yayadipuro dan Kyai Sindusastra dalam lakon Arjunasasra atau Lokapala (Kitab Arjuna Wijaya pupuh Sinom bait 26). Sastra jendra adalah hakikat ma'rifat atau ujung perjalanan dari segala ilmu. Sastra jendra merupakan ilmu tentang manunggaling kawula lan gusti (menjadi satunya manusia dengan Tuhan). Tidak sembarang orang dapat mempelajari dan menerapkan ilmu tersebut karena ilmu ini bukanlah yang tampak pada mata, tetapi yang ada dan tampak dalam mata hati.

Nafsu antara Wisrawa dan Sukesi ini muncul dalam aktivitas mempelajari Sastra Jendra Hayuningrat Pangruwating Diyu yang merupakan ilmu spiritual tertinggi pada saat itu. Bathara Guru dan Bathari Durga yang merasuki tubuh Begawan Wisrawa dan Dewi Sukesi dan menimbulkan nafsu birahi yang luar biasa. Di sinilah Wisrawa tidak mampu 
menahan nafsunya seperti raksasa yang kemudian melahirkan kehinaan karena nafsu yang salah dilepaskan.

Hubungan mereka berdua akhirnya membuahkan kehamilan dewi Sukesi. Dari hubungan tersebut, lahirlah empat orang anak, yaitu Dasamuka, Kumbakarna, Sarpakenaka, dan Gunawan Wibisana. Tiga di antaranya menggambarkan nafsu keduniawian dan yang terakhir merupakan gambaran dari pertaubatan yang menghasilkan kesucian.

Pertama adalah Dasamuka. Dia berwujud raksasa besar yang mengerikan. Dia memiliki ajian pancasona (sepuluh wajah) sehingga ketika dipenggal dia dapat hidup lagi hingga sepuluh kali. Wajahnya berwarna merah bagaikan api yang menyala. Dasamuka memiliki watak yang sangat jahat dan dalam kehidupannya, hanya mengedepankan hawa nafsu dan mudah marah. Senjatanya adalah candrasa. Walaupun sakti, namun pada akhirnya mati oleh panah guhwawijaya milik Ramawijaya.

Kedua adalah Kumbakarna. Kumbakarna adalah raksasa yang memiliki perawakan yang tinggi dan sangat besar melebihi gunung serta wajahnya berwarna hijau gelap. Kumbakarna melambangkan nafsu makan dan tidur yang berlebihan. Kumbakarna tinggal di Lemburgangsa. Senjatanya adalah aji-aji gedhonmenga dan pelak gelak sakethi. Kumbakarna mati dalam peperangan untuk mempertahankan tanah airnya dari serangan tentara kera Rama.

Ketiga adalah Sarpakenaka. Sarpakenaka adalah anak perempuan yang berwujud raksasa. Wataknya sangat jahat dan suka iri hati atas kebahagiaan orang lain. Wajahnya jelek berwarna kuning dan suka bersolek berlebihan. Sarpakenaka menjadi lambang bagi nafsu birahi dan harta dunia.

Keempat adalah Gunawan Wibisana. Anak terakhir yang sangat berbeda dengan ketiga kakaknya. Gunawan Wibisana berparas tampan dan berhati halus. Dia berwujud kesatria dengan wajah putih halus yang melambangkan kesukaan pada hidup sederhana dan spiritualitas yang tinggi. Dia merupakan raja Alengka selanjutnya setelah Dasamuka.

Perbedaan keempat anak tersebut terjadi karena watak orang tuanya pada saat "melakukan" dan pada saat pertumbuhan kehamilan istrinya. Ketiga anaknya yang berwujud raksasa lahir karena sifat penuh dengan nafsu duniawi, sedangkan anak terakhir lahir pada saat orang tuanya mulai sadar dan kembali kepada jalan spiritual yang berdasar pada norma-norma asmaragama. Hal ini menandakan bahwa setinggi apapun ilmu manusia, dia harus selalu ingat dan sadar. Seperti petuah Jawa yang biasa diucapkan oleh orang tua kepada anaknya yaitu "Sabegja-begjane wong kang lali, luwih begja wong kang eling lan waspada". Kewaspadaan yang ditandai dengan kesadaran, kesabaran, dan ketelitian hendaknya selalu berada dalam diri manusia (Narimo, 2010, p. 10).

Dalam mitologi dan legenda yang muncul, raksasa adalah bangsa makhluk yang menyerupai hewan. Mereka berukuran lebih besar daripada ukuran normalnya manusia. Dongeng dan legenda menyatakan bahwa raksasa merupakan bangsa makhluk yang memiliki nafsu tinggi terhadap hal yang bersifat keduniawian. Raksasa juga merupakan makhluk yang bodoh dan bengis, suka mengganggu, rakus, senang berfoya-foya, hidup bebas, sombong, dan sangat jahat.

Lain halnya dengan Kumbakarna, meskipun dia berwujud raksasa namun berbeda dengan kedua saudaranya yang juga tergolong raksasa. Kumbakarna adalah raksasa yang berjiwa kesatria. Dia selalu melakukan darma yang baik sehingga disenangi oleh dewa. Sebelum terjadi perang di Ngalengka seperti yang tertuang dalam Serat Tripama, kumbakarna adalah raksasa yang senang bertapa. Darma yang dia lakukan kepada Dewa tersebut disukai oleh Batara Brahma. Iapun diberi kebebasan untuk menentukan pilihan hadiah yang diinginkannya. Saat Batara Brahma dan Batari Saraswati menemui Kumbakarna menanyakan apa yang diminta, Kumbakarna meminta indrasan, yaitu keistimewaan untuk menjalani hidup mewah di Negeri Kahyangan Kaendran yang dimiliki oleh Dewa Indra. Rasa puas dalam dirinya yang tinggi dan terlalu bahagia atas hadiah yang akan dia terima, menyebabkan Kumbakarna salah mengucap. Ucapan indrasan berubah menjadi nendrasan yang berarti tidur panjang. Maka Kumbakarna pun mengalami tidur panjang di Gunung Gohkarna sampai pada Perang Ngalengka.

Dalam Serat Tripama Karya Mangkunegara IV pupuh Dandanggula bait ke tiga dan ke empat dijelaskan tentang Kumbakarna sebagai berikut: 
Wonten malih tuladan prayogi,

Satriya gung nagari Ngalengka,

Sang Kumbakarna namane,

Tur iku warna diyu,

Suprandene nggayuh utami,

Duk awit prang Ngalengka,

Dennya darbe atur,

Mring raka amrih raharja,

Prabu Dasamuka tan keguh ing atur yekti,

De mung mungsuh wanara.

Artinya:

Ada lagi teladan baik,

Satria agung dari negara Ngalengka,

Sang Kumbakarna namanya,

Padahal dia bersifat raksasa,

Namun demikian dia berusaha meraih

keutamaan,

Sejak perang di Ngalengka,

Ia mengajukan pendapat,

Kepada kakandanya agar selamat,

Prabu Dasamuka tak tergoyahkan oleh

pendapat baik,

Karena hanya melawan kera.

Selanjutnya pada bait ke empat adalah :

Kumbakarna kinen mangsah jurit,

Mring kang rak sira tan lenggana,

Nglungguhi kasatriyane,

Ing tekad datan purun,

Amung cipta labih nagari,

Lan nolih yayahrena,

Myang luluhuripun,

Wus mukti aneng Ngalengka,

Mangke arsa rinusak ing bala kali,

Punagi mati ngrana.

Artinya:

Kumbakaran diperintah maju perang,

Oleh kakandanya, ia tidak menolak,

Menepati kesatriaannya,

Dalam tekadnya tak mau,

Hanya demi membela negara,

Dan mengangkat ayah-bundanya,

Telah hidup nikmat di negeri Ngalengka,

Sekarang akan dirusak oleh barisan kera,

Bersumpah mati dalam perang.

Berdasarkan Tembang Dandanggula dalam Serat Tripama di atas, digambarkan bahwa Kumbakarna adalah tokoh raksasa yang memiliki jiwa manusia utama. Hal ini nampak dari kebiasaannya melakukan darma dan bertapa. Dia juga tidak mudah terbawa hawa nafsu duniawi yang berlebihan kecuali makan dan tidur. Kumbakarna juga merupakan raksasa yang dapat berfikir logis dan membedakan mana yang benar dan mana yang salah.

Kumbakarna gugur yang dimainkan oleh Ki Enthus Susmono. Diceritakan Kumbakarna yang dibangunkan oleh kakaknya untuk maju berperang melawan tentara kera pimpinan Sri Rama. Sebelum berperang, Kumbakarna mencari tahu tentang hal yang terjadi hingga bala tentara kera Sri Rama menyerang Ngalengka dan membinasakan banyak tentara Ngalengka. Setelah tahu sebab dari adanya perang tersebut, Kumbakarna berusaha menasihati Rahwana kakaknya agar mengembalikan Sinta yang merupakan istri Sri Rama dari Ayodya kepada suaminya. Sinta bukanlah miliknya dan berdosa apabila menginginkan milik orang lain. Akan tetapi, Rahwana sama sekali tidak memperdulikan nasehat dari adiknya tersebut. Dia tetap ingin memiliki Sinta dan ingin terus berperang sampai titik darah terakhir.

Setelah nasehatnya tidak dihiraukan oleh kakaknya Kumbakarna pun turun ke medan peperangan. Dia berada dibarisan depan sebagai panglima. Namun munculnya Kumbakarna di medan peperangan. Ia bukan berperang untuk membela kakaknya yang salah, tetapi untuk mempertahankan negaranya yang sebentar lagi hancur oleh tentara kera Sri Rama.

Dalam peperangan yang berlangsung, semua kesatria Ayodya dan kesatria kera yang terluka atau mati di tangan Kumbakarna, dia perlakukan dengan hormat. Ia menjunjung tinggi sikap kesatria sebagai sesama patriot. Namun akhirnya, Kumbakarna pun tewas oleh panah Sri Rama yang memutus kedua tangan, kedua kaki, dan lehernya. Karena sikap patriotisme dan nasionalismenya tersebut, dihari kematian Kumbakarna, Sri Rama melakukan gencatan senjata sebagai penghormatan kepada Kumbakarna atas keberanian, dan semangat bertempur sebagai seorang patriot.

Penjelasan tersebut dapat ditarik simpulan bahwa Kumbakarna memiliki karakter yang patriotisme, rela berkorban, dan bertanggung jawab. Meskipun dia merupakan raksasa namun dia memiliki sikap membela tanah airnya yang sebentar lagi hancur. Kisah menge- 
nai tokoh Kumbakarna ini mengandung nilai nasionalisme yang baik untuk dijadikan teladan.

\section{Adipati Karna}

Tokoh ketiga dalam Serat Tripama karya Mangkunegara IV adalah Basukarna atau Adipati Karna atau Suryatmaja atau Suryaputera. Adipati Karna ketika masih muda bernama Suryaputera. Suryaputera adalah anak dari Dewi Kunthi Talibrata dari negara Mandura dengan Batara Surya. Suryaputera lahir karena mantra pemberi anak "aji pameling" yang diberikan oleh Resi Druwasa yang bernama mantra kuntawekasing tunggal tanpa lawan yang diucapkan oleh Dewi Kunthi. Mantra tersebut dapat mendatangkan dewa sesuka hatinya dan ilmu tersebut berkaitan dengan permintaan anak. Ilmu yang diuji cobakan itu, akhirnya mendatangkan dewa Surya yang selanjutnya memberikan seorang bayi di dalam perutnya. Akan tetapi karena Suryaputera adalah anak yang tercipta di luar ikatan resmi, maka akhirnya dia dibuang ke sungai untuk menutupi aib.

Setelah dibuang Suryaputera ditemukan oleh kusir kuda dari Astina bernama Adirata. Suryaputera kemudian dibesarkan hingga dewasa oleh Adirata dan istrinya Nanda. Suryaputera diberinama oleh Adirata dengan nama Basukarna. Dia besar sebagai lakilaki yang tampan, gagah, dan memiliki kesaktian yang sama dengan Arjuna. Sejatinya, mereka adalah saudara seibu lain bapak.

Basukarna hebat bukan hanya karena titisan dewa. Kehebatannya juga dikarenakan mencuri pembelajaran memanah dari Guru Durna yang sedang mengajarkan ilmunya kepada Kurawa dan Pandhawa. Setiap pagi saat hendak memandikan kuda kerajaan, ia melihat Guru Durna mengajar memanah. Walaupun dia hebat, namun dia tidak mendapatkan perhatian bahkan dibuang dari Astina karena mempertontonkan keahliannya. Hal tersebut, tidak sepantasnya dia lakukan karena dia berasal dari kasta bawah dan dianggap sebuah kesombongan yang memiliki sanksi, diusir dari kerajaan.

Kelicikkan Duryudanalah yang menjadikan Basukarna dari anak kusir biasa menjadi raja di Awangga. Basukarna kemudian terkenal dengan nama Adipati Karna. Karena terikat hutang budi kepada Duryudana atau
Kurupati, maka dia mau menyerahkan hidup dan matinya pada Duryudana. Sampai suatu saat, Duryudana anak dari Destarastra dan Dewi Gendari menunjuk Adipati Karna sebagai panglima perangnya dalam Perang Bharatayuda.

Kisah selanjutnya, tentang Suryaputra. Dia adalah suami dari Surtikanthi dan menantu dari Prabu Salya. Dia memiliki dua senjata andalan yang diberikan oleh Dewa Indra yaitu kotang antakusuma dan senjata kunta baskara. Kotang antakusuma menjadikannya kebal terhadap senjata dan kunta baskara adalah panah yang dapat menimbulkan kehancuran dasyat.

Ketika Perang Bharatayuda terjadi, Adipati Karna baru mengetahui jika Kunthi adalah ibunya. Adapun musuh-musuhnya yaitu Pandawa merupakan adik-adiknya dari ibu yang sama. Pada saat itu Kunthi, ibu kandungnya, memintanya untuk bergabung dalam barisan perang Pandawa namun ia menolak. Dia memilih bertarung dengan Arjuna, adik seibu yang seimbang kepiawaiannya dalam memanah. Hal ini dikarenakan dia berutang budi pada Raja Duryudana dan telah bersumpah untuk setia kepada yang memberinya pangkat dan kedudukan, dan memegang teguh janjinya sebagai sumpah setia untuk membalas budi karena telah mengangkat derajatnya menjadi seorang raja. Loyalitas tersebut, ia buktikan hingga hembusan nafas terakhirnya. Dalam Serat Tripama ini dilukiskan watak Adipati Karna yang patut untuk diteladani setelah dia diangkat sebagai Raja di Awangga oleh Duryudana. Pada tembang dhandanggula bait ke lima dan ke enam yang berisi mengenai Suryaputera sebagai berikut :

Wonten malih kinarya palupi,

Suryaputra Narpati Ngawangga,

Lan Pandhawa tur kadange,

Len yayah tunggil ibu,

Suwita mring Sri Kurupati,

Aneng nagri Ngastina,

Kinarya gul-agul,

Manggala golonganing prang,

Bratayuda ingadegken senapati,

Ngalaga ing Korawa.

Artinya:

Baik pula untuk teladan,

Suryaputera raja Ngawangga,

Dengan Pandawa adalah saudaranya,

Berlainan ayah tunggal ibu, 
Mengabdi kepada Sri Kurupati,

Dari Negara Ngastina,

Dijadikan andalan,

Bratayuda sebagai panglima,

Perang di pihak Korawa.

Selanjutnya pada bait ke enam adalah sebagai berikut:
Minungsuhken kadange pribadi,
Aprang tandhing lan sang Dananjaya,
Sri Karna suka manahe,
Dene sira pikantuk,
Marga dennya arsa males-sih,
Ira sang Duryudana,
Marmanta kalangkung,
Dennya ngetog kaSudiron,
Aprang rame Karna mati jinemparing,
Sumbaga wirotama.

Artinya:

Dihadapkan dengan saudaranya sendiri, Perang tanding melawan Dananjaya,

Sri Karna suka hatinya,

Karena ia memperoleh jalan untuk

membalas cinta kasih,

Sang Duryudana,

Maka ia dengan sangat,

Mencurahkan segala keberaniannya,

Perang seru Karna mati dipanah,

Mashur sebagai perwira utama.

Berdasarkan tembang macapat tersebut pada intinya berisi tentang tokoh Suryaputera atau Adipati Karna yang juga patut untuk dijadikan contoh bagi kita. Hal demikian dapat kita lihat dari pengorbanannya terhadap Duryudana dan negara Astina yang telah memuliakan hidupnya dan mengangkat derajatnya dari anak kusir kuda menjadi Raja di Awangga.

Pengorbanan yang dilakukan Adipati Karna adalah ketika dia tetap maju Perang Baratayuda dipihak Kurawa dan harus melawan Pandawa yang jelas-jelas dia ketahui bahwa Pandawa masih saudaranya sendiri. Majunya Suryaputra dalam perang dilakukannya atas berbagai pertimbangan antara lain:

1) Adipati Karna lebih memilih dipihak Kurawa daripada Pandhawa. Menurutnya Kurawa adalah sosok yang menerimanya apa adanya dengan tidak melihat kasta tetapi kemampuan.

2) Sejak kecil dia tumbuh dan berkembang di Awangga daerah kekuasaan Astina jadi sudah sepantasnya dia membela tanah airnya.

3) Dia ingin menjalankan janjinya untuk setia kepada orang yang sudah meninggikan derajatnya dan memberikan pangkat kepadanya.

Sikap yang diambil oleh Adipati Karna ini menggambarkan bahwa dia adalah tokoh yang memiliki karakter teguh pendirian, tanggung jawab, jiwa kesatria dan tidak melupakan jasa atau kebaikan orang lain. Hal ini, nampak jelas bahwa pembelaannya dipihak Kurawa karena di satu sisi membela tanah air yang telah membesarkannya, di sisi lain dia juga merasa berhutang budi pada Duryudana yang telah menerima apa adanya. Semua kebaikan yang telah diterimanya merupakan tanggung jawab yang besar dan dia berkeyakinan harus membalasnya.

Nilai-nilai dalam Serat Tripama tersebut memiliki makna keteladanan bagi penguatan rasa kewajiban dan tanggung jawab terhadap bangsa dan negara. Serat Tripama karya Mangkunegara IV memiliki nilai-nilai ajaran yang relevan untuk diketahui, diajarkan, diamalkan, dan digunakan sebagai modal pendidikan karakter dimasa setelah kemerdekaan sekarang ini.

Selanjutnya, nilai karakter yang perlu dicontoh adalah sifat-sifat keprajuritan yang menjadi keutamaan seseorang yang mengabdi kepada raja dan negara. Nilai-nilai karakter yang dapat diteladani dari ketiga tokoh di Tripama (Patih Suwanda, Kumbakarna, dan Adipati Karna) adalah sebagai berikut.

\section{Patih Suwanda}

Mengajarkan nilai-nilai karakter yang dapat diteladani bagi generasi penerus bangsa yaitu: (1) cinta tanah air, (2) pandai, (3) berfikir sebelum bertindak, (4) penuh perhitungan, (5) mau mengabdi kepada negara, (6) setia kepada raja, (7) tanggung jawab, (8) berani, (9) mengutamakan kewajiban, dan (10) patriotik

\section{Kumbakarna}

Kumbakarna memiliki nilai-nilai yang dapat diteladani bagi generasi penerus bangsa yaitu: (1) berbudi luhur, (2) berfikir rasional, (3) berani, (4) cinta tanah air, (5) selalu ingin meraih keutamaan, (6) adil, dan (7) patriotik. 


\section{Adipati Karna}

Adipati Karna memiliki beberapa nilai yang dapat diteladani bagi generasi penerus bangsa yaitu: (1) cinta terhadap tanah air, (2) setia kepada raja yang memberinya kedudukan, (3) menepati janji, (4) memiliki prinsip dalam hidup, (5) tahu balas budi, (6) tegas dan tidak mudah goyah, (7) patriotik, dan (8) berani.

Dua diantaranya memiliki kesetiaan kepada negara dan rajanya. Adapun Kumbakarna, ia hanya memiliki kesetiaan kepada negara bukan kepada raja. Kesadaran akan bela negara yang tinggi ada di dalam diri ketiga tokoh wayang tersebut. Meskipun mereka mengetahui pada akhirnya mereka akan kalah dan gugur, namun mereka tetap maju berperang. Sifat kesetiaan dan keberanian seorang prajurit adalah hal yang utama untuk menjaga keamanan dan ketentraman di sebuah negara.

Secara umum, isi Serat Tripama mengandung pesan yaitu: (1) tiap-tiap warga negara mempunyai kewajiban membela tanah airnya, (2) ajaran tentang cinta tanah air dan wajib bela negara itu juga bisa kita temukan dalam ungkapan-ungkapan tradisional, (3) dalam menilai suatu hal kita perlu cermat dan hati-hati, harus bisa membedakan baik buruknya secara tepat, (4) kepentingan bangsa dan negara harus lebih diutamakan daripada kepentingan pribadi dan golongan, (5) kepentingan bangsa dan negara harus kita lakukan dengan sepenuh hati, (6) seseorang akan tumbuh sikap hidup jika selalu memperlakukan orang lain secara manusiawi (Prabowo, 2003, p. 44). Sedangkan menurut Catur Nugroho sebagai dalang di daerah Sambi Boyolali, nilai yang dapat diambil diantaranya: nilai kepahlawanan, nilai kesetiaan, nasionalisme, pengorbanan, dan jiwa kesatria yang selalu diutamakan. Nilai-nilai nasionalisme ini sangat relavan apabila dikolerasikan sebagai perspektif pendidikan karakter bagi generasi muda pada masa sekarang karena sangat berpengaruh besar bagi kemajuan atau kemundurun suatu bangsa.

Naskah-naskah kuno tersebut dapat digunakan sebagai sumber untuk menggali nilai-nilai luhur bangsa sebagai modal budaya (culture capital) dan modal sosial (social capital). Upaya menggali, menguji, mensosialisasi dan mengkulturasi tata nilai luhur perlu terus ditingkatkan, dan didukung dengan memperluas aplikasi modal budaya dan osial, sebagai sumber yang dapat ditransformasikan menjadi nilai tambah dalam membangun karakter bangsa.

Pendidikan karakter berbasis budaya dalam lingkungan pendidikan informal ternyata mampu menghasilkan warga negara yang baik. Hal ini didukung oleh beberapa penelitian mengenai pengaruh pendidikan berbasis budaya lokal terhadap pembentukan karakter. Salah satunya, mengenai tembang karena budaya macapat masih dianggap relevan sebagai sarana dan wahana dalam pembangunan karakter bangsa (Machfiroh, 2011; Wardhani, 2016).

\section{SIMPULAN}

\section{Simpulan}

Ketiga tokoh yang digambarkan dalam Serat Tripama ini, hanya satu yang dapat dijadikan teladan atas perilakunya yaitu Patih Suwanda yang memiliki tekad kuat untuk mengabdi kepada raja yang arif dan bijaksana dengan terlebih dahulu mengasah kemampuannya untuk bekal mengabdi. Sedangkan Kumbakarna dan Adipati Karna merupakan contoh yang buruk karena dinilai tidak rasional dalam pengabdiannya yang diperuntukkan untuk raja yang jahat meskipun telah dijelaskan kerelaannya berkorban bukan untuk raja namun untuk negara.

\section{Saran}

Karya sastra dibuat bukan tanpa tujuan dan sasaran maka dari itu penting untuk mengetahui tujuan sebenarnya. Dengan demikian, diperoleh pemaknaan yang benar tentang karya sastra. Salah penafsiran yang dilakukan di bidang pendidikan khusunya karakter akan berakibat sebaliknya dapat merusak karakter.

\section{DAFTAR PUSTAKA}

Abdullah, A. (2006). Khasanah budaya karaton Yogyakarta. Makalah seminar di UIN Yogyakarta, 15 November 2006.

Cahyono, B. (2015). Nilai pendidikan karakter dalam serat tripama dan relevansinya dengan pembelajaran apresiasi sastra jawa (kajian heuristik dan hermeneustik). Disertasi, tidak 
dipublikasikan Universitas Negeri Sebelas Maret.

Dieter, M. (2001). Pendidikan musik antara harapan dan realita. Bandung: UPI Masyarakat Seni Pertunjukan Indonesia.

Hikmat, H. (2010). Strategi Pemberdayaan Masyarakat. Bandung: Humaniora Utama Press.

Machfiroh, R. (2011). Revitalisasi karakter bangsa melalui pendidikan kewarganegaraan dengan pengembangan budaya lokal: studi kasus budaya ma-capat di kota surakarta. Tesis, tidak dipublikasikan Universitas Pendidikan Indonesia.

Miles, M., \& Huberman, A. M. (1992). Analisis data kualitatif.buku sumber tantang metode-metode baru. Jakarta: UI Press.
Narimo, S. (2009). Karakteristik Psiko-Sosio Kultural Manusia Dalam Serat Wulang Reh Karya Pakoe Boewono IV (Tinjauan Pendidikan Informal Masyarakat Jawa). Disertasi, tidak dipublikasikan. Universitas Negeri Jakarta.

Saputro, K. H. (2001). Puisi Jawa Struktur dan Etika. Jakarta: Wedatama Widya Sastra.

Supriyono, \& Sutono, A. (2014). Identifikasi Nilai-Nilai Keutamaan dalam Serat Tripama Sebagai Bentuk Pengembangan Pendidikan Berbasis Budaya. Jurnal Ilmiah CIVIS IV.(2). 42-52

Wardhani, Novia Wahyu. (2016). Pembelajaran Nilai-nilai Kearifan Lokal Sebagai Penguat Karakter Bangsa Melalui Pendidikan Informal. Jurnal Penelitian Pendidikan, 13(1). 